\title{
Clinical outcomes of acute respiratory distress syndrome in a university hospital
}

\author{
Natthawan Sanguanwong*, Napplika Kongpolprom
}

\begin{abstract}
Background: Mortality rates of acute respiratory distress syndrome (ARDS) are different, depending on severity, etiology, and management.

Objective: To determine 7-day and 28-day mortalities, hospital length of stay (LOS), duration of mechanical ventilation (MV) of ARDS patients, and factors associated with poor outcomes.

Methods: A retrospective study was conducted to review the database of ARDS patients admitted in medical intensive care units (ICUs) at a university hospital between 2010 and 2014. The cases were identified by using International Classification of Diseases, 10th Revision (ICD-10) code-J80 ARDS.

Results: Of 266 patients, $11.7 \%, 44.4 \%$, and 44\% fulfilled mild, moderate, and severe ARDS criteria, respectively. The main cause of ARDS was pneumonia. The 7-day and 28-day mortalities, median LOS, and median MV duration were $31.1 \%, 69.3 \%, 18$, and 11 days, respectively. Pressure control was the most favorite mode, used with average tidal volume (TV) of $8.63(2.16) \mathrm{mL} / \mathrm{kg}$ ideal body weight (IBW). Recruitment maneuver was most frequently used as adjunctive intervention, whereas prone position was applied to $3.75 \%$ of the patients. One-third of the patients received neuromuscular blockades. The median 7-day fluid balance was $+6,600 \mathrm{~mL}$. The mean $\mathrm{PaO}_{2} / \mathrm{FiO}_{2}$ ratio during the first 3 days, cumulative fluid balance on day 3 , and average daily calories during the first week were independent predictors for adjusted 7-day mortality, whereas Acute Physiology and Chronic Health Evaluation (APACHE II) score, fluid balance on day 1, cumulative fluid balance, and average daily calories during the first week were independent predictors for adjusted 28-day mortality.

Conclusions: The 28-day mortality of ARDS was high. In addition, TV and fluid balance were greater than protective limits. These findings indicated the potential improvement of ARDS outcomes in our hospital.
\end{abstract}

Keywords: acute respiratory distress syndrome; intensive care units; positive pressure respiration

Acute respiratory distress syndrome (ARDS) is characterized by severe hypoxemia and non-cardiogenic pulmonary edema. In 1967, Ashbaugh et al. [1] reported a case series of 12 critically ill patients with tachypnea and hypoxemia accompanied by decreased lung compliance and pulmonary infiltrates on chest X-rays from different etiologies. This was the first established ARDS. Thenceforth, there was no common definition of ARDS [2], resulting in various published prevalences in intensive care units (ICUs). Until 2012, Berlin definition of ARDS was created by a consensus panel of experts (an initiative of the European Society of Intensive Care Medicine endorsed by the American Thoracic Society and the Society of Critical Care Medicine) to simplify the diagnosis and prognosticate outcomes [3]. ARDS was defined as a clinical entity, which consisted of an acute onset (less than 1 week), bilateral opacities on computed tomography or chest radiograph, a ratio

*Correspondence to: Natthawan Sanguanwong, Department of Medicine, Faculty of Medicine, Chulalongkorn University, Bangkok 10330, Thailand, e-mail: Nabpalika.K@chula.ac.th

Department of Medicine, Faculty of Medicine, Chulalongkorn University, Bangkok 10330, Thailand

¿ Open Access. ๑ 2018 Sanguanwong and Kongpolprom, published by Sciendo. (cc) BY-NC-ND This work is licensed under the Creative Commons Attribution NonCommercial-NoDerivatives 4.0 License. 
of the partial pressure of arterial oxygen to the fraction of inspired oxygen $\left(\mathrm{PaO}_{2} / \mathrm{FiO}_{2}\right.$ ratio $) \leq 300 \mathrm{mmHg}$ with a minimum of $5 \mathrm{~cm} \mathrm{H}_{2} \mathrm{O}$ positive end-expiratory pressure (PEEP), and no cardiac failure or fluid overload.

ARDS is associated with high mortality. For over 20 years, many therapeutic strategies have been provided to improve patients' outcomes. In 2000, the ARDS network established an important study "Ventilation with lower tidal volumes as compared with traditional tidal volumes for ALI and ARDS." The study demonstrated that the use of low tidal volume (TV; $6 \mathrm{~mL} / \mathrm{kg}$ predicted weight) significantly reduced mortality from $40 \%$ to $30 \%$ and increased ventilator-free days, compared with traditional TV $(12 \mathrm{~mL} / \mathrm{kg}$ predicted weight $)$ [4]. In 2010, the ACURASYS study investigators reported that the use of neuromuscular blockade (cisatracurium) in patients with early ARDS with $\mathrm{PaO}_{2} / \mathrm{FiO}_{2}$ ratio $<150$ for $48 \mathrm{~h}$ significantly reduced both 28 -day and 90 -day mortalities and increased ventilator-free days without increased incidence of ICU-acquired weakness [5]. In addition, PROSEVA study showed that prone position with lung-protective strategy reduced 28-day and 90-day mortalities and this strategy should be considered in patients with early ARDS and severe hypoxemia who have the $\mathrm{PaO}_{2} / \mathrm{FiO}_{2}$ ratio of $<150$ despite $\mathrm{FiO}_{2}$ of $\geq 0.6$ and PEEP of $\geq 5 \mathrm{~cm} \mathrm{H}_{2} \mathrm{O}$ [6].

On the contrary, some strategies did not improve survival and might be harmful to ARDS patients. There were 2 landmark studies of high-frequency oscillation ventilation (HFOV), including OSCAR and OSCILATE trials $[7,8]$. The former study showed that HFOV did not reduce mortality and increased the need of sedatives and muscle relaxants. The latter study showed that HFOV increased hospital mortality ( $47 \%$ in the HFOV group vs $35 \%$ in the low TV with the high PEEP group) and the need of sedatives, muscle relaxants, and vasopressors. Furthermore, a recent study showed that lung recruitment with PEEP set by respiratory system compliance significantly increased 28-day and 6-month mortalities with higher incidences of barotrauma and hypotension in moderate to severe ARDS patients [9].

Besides the ventilator management, several trials demonstrated benefits of conservative fluid management in patients with ARDS [10-13]. The Fluid and Catheter Treatment Trial (FACTT) demonstrated that a conservative fluid management strategy improved oxygenation, shortened duration of mechanical ventilation (MV), and ICU stay without a risk of nonpulmonary organ failure in ARDS patients [10]. However, it did not show a mortality benefit and potentially increased a risk of long-term cognitive impairment [14].

Epidemiological studies of the practice and outcomes of ARDS were mostly conducted in high-income countries, and the data in low- to middle-income countries were still limited. Moreover, some studies such as LUNG SAFE study were not focused on ARDS patients [15]. We hypothesized that routine clinical practice and outcomes of ARDS in our hospital might be different from the previous reported data from developed countries due to limited ICU resource and shortage of health care personnel. This study aimed to evaluate the clinical outcomes of ARDS patients, associated factors predicting outcomes, and current physicians' practice in our medical ICUs.

\section{Materials and methods}

\section{Study design}

We conducted a retrospective cross-sectional study of clinical outcomes of ARDS patients and physicians' practice in the medical ICUs at tertiary referral university teaching hospital. We included all ARDS patients admitted in the medical ICUs from September 2010 to September 2014. The patients were identified using the International Classification of Diseases, 10th Revision, Clinical Modification (ICD-10-CM) code: J80 (ARDS) and Diagnosis and Procedure Codes (ICD-9-CM) codes: 997x, 96.7. The data were collected from inpatient medical records. Only patients with fulfilled ARDS criteria (Berlin definition) were reviewed and analyzed. This study was approved by the Institutional Review Board (IRB) of the Faculty of Medicine, Chulalongkorn University, for authorization for medical record review (approval certificate no. 457/59). The clinical trial registration number is TCTR20180212002.

\section{Eligibility criteria}

ARDS patients admitted in medical ICUs at tertiary referral university teaching hospital with 14 beds in ICU between September 2010 and September 2014, using the raw data that made up the various components of the Berlin ARDS definition [3].

\section{Statistical analyses}

Acute Physiology and Chronic Health Evaluation (APACHE II) was determined at the onset of ARDS. Other recorded variables included age, sex, etiology, blood gas analysis, ventilator management, and clinical outcomes of ARDS. The primary outcome was 28-day mortality. The secondary outcomes 
were 7-day mortality, and other clinical outcomes were hospital length of stay (LOS) and duration of MV, and ventilator management.

SPSS (versions 22) was used to analyze the data, using odds ratio (OR), $P$-value, and $95 \%$ confidence intervals (CIs). Univariate and multivariate analyses (using variables with $P<0.2$ in univariate analysis) for 7- and 28-day mortalities were performed using a binary logistic regression model.

\section{Results}

Between 2010 and 2014, 266 of 4,090 (6.5\%) patients admitted in our medical ICUs met the Berlin criteria for ARDS diagnosis. Approximately $11.7 \%, 44.4 \%$, and $44.0 \%$ of the patients fulfilled mild, moderate, and severe ARDS criteria, respectively. The severity of ARDS correlated with APACHE II score $\left(r^{2}=0.235, P<0.001\right)$. Demographic data of the patients are summarized in Table 1.

The majority of the ARDS patients had pneumonia and were assisted with pressure-controlled ventilation with the mean peak inspiratory pressure (PIP) and PEEP on the first day of MV of $31 \pm 6$ and $10 \pm 4 \mathrm{~cm} \mathrm{H}_{2} \mathrm{O}$, respectively. The plateau pressure (Pplat) was recorded in only $4.1 \%$ of the patients. The mean TV on the first day was $8.56 \pm 2.48 \mathrm{~mL} / \mathrm{kg}$ ideal body weight (IBW), and the average TV during the first 3 days of MV was $8.81 \pm 2.39 \mathrm{~mL} / \mathrm{kg}$ IBW. Approximately $55.4 \%$ of the patients had TV on the first day of MV of $>8 \mathrm{~mL} / \mathrm{kg}$ IBW and $60.9 \%$ of the patients had average TV during the first 3 days of MV of $>8 \mathrm{~mL} / \mathrm{kg}$ IBW.

Table 1. Characteristics of enrolled patients

\begin{tabular}{|c|c|c|c|c|}
\hline & Overall & Mild ARDS & Moderate ARDS & Severe ARDS \\
\hline $\mathrm{N}(\%)$ & $266(100.0 \%)$ & $31(11.7 \%)$ & $118(44.4 \%)$ & $117(44.0 \%)$ \\
\hline Age (years), mean $\pm S D$ & $54.81 \pm 18.66$ & $48.84 \pm 21.40$ & $53.67 \pm 18.64$ & $57.54 \pm 17.56$ \\
\hline \multicolumn{5}{|l|}{ Gender, n (\%) } \\
\hline Male & $153(57.5 \%)$ & $16(51.6 \%)$ & $66(55.9 \%)$ & $71(60.7 \%)$ \\
\hline Female & $113(42.5 \%)$ & $15(48.4 \%)$ & $52(44.1 \%)$ & $46(39.3 \%)$ \\
\hline $\mathrm{BMI}\left(\mathrm{kg} / \mathrm{m}^{2}\right)$, mean $\pm \mathrm{SD}$ & $22.21 \pm 4.44$ & $21.91 \pm 3.59$ & $21.96 \pm 3.97$ & $22.56 \pm 5.11$ \\
\hline \multicolumn{5}{|l|}{ Etiology of ARDS (\%) } \\
\hline Pneumonia & $217(81.6 \%)$ & $26(83.9 \%)$ & $100(84.7 \%)$ & $91(77.8 \%)$ \\
\hline Sepsis & $25(9.4 \%)$ & $4(12.9 \%)$ & $6(5.1 \%)$ & $15(12.8 \%)$ \\
\hline HLH & $3(1.1 \%)$ & $0(0 \%)$ & $2(1.7 \%)$ & $1(0.9 \%)$ \\
\hline Pneumonitis & $10(3.8 \%)$ & $1(3.2 \%)$ & $4(3.4 \%)$ & $5(4.3 \%)$ \\
\hline Multiple factors & $6(2.3 \%)$ & $0(0 \%)$ & $5(4.2 \%)$ & $1(0.9 \%)$ \\
\hline Unspecified cause & $2(0.8 \%)$ & $0(0 \%)$ & $1(0.8 \%)$ & $1(0.9 \%)$ \\
\hline Diffuse alveolar hemorrhage & $3(1.1 \%)$ & $0(0 \%)$ & $0(0 \%)$ & $3(1.1 \%)$ \\
\hline APACHE II median ( $25 \%, 75 \%$ quartile) & $26(22,31)$ & $23.16(19,27)$ & $25.09(21,29)$ & $27.69(23,32)$ \\
\hline $\mathrm{PaO}_{2} / \mathrm{FiO}_{2}$, day 1 , mean $\pm \mathrm{SD}$ & $122.40 \pm 58.64$ & $237.88 \pm 53.81$ & $138.96 \pm 28.08$ & $75.29 \pm 18.04$ \\
\hline \multicolumn{5}{|l|}{ Initial mode (\%) } \\
\hline PCV & $233(87.6 \%)$ & $22(71 \%)$ & 105 (89\%) & $106(90.6 \%)$ \\
\hline VCV & $5(1.9 \%)$ & $1(3.2 \%)$ & $2(1.7 \%)$ & $2(1.7 \%)$ \\
\hline PSV & $14(5.3 \%)$ & $4(12.9 \%)$ & $5(4.2 \%)$ & $5(4.3 \%)$ \\
\hline SIMV & $2(0.8 \%)$ & $1(3.2 \%)$ & $1(0.8 \%)$ & $0(0 \%)$ \\
\hline NIV & $7(2.6 \%)$ & $2(6.5 \%)$ & $1(0.8 \%)$ & $4(3.4 \%)$ \\
\hline Bird mark 7 & $4(1.5 \%)$ & $0(0 \%)$ & $4(3.4 \%)$ & $0(0 \%)$ \\
\hline Nasal high flow & $1(0.4 \%)$ & $1(3.2 \%)$ & $0(0 \%)$ & $0(0 \%)$ \\
\hline \multicolumn{5}{|l|}{ Adjunctive interventions (\%) } \\
\hline APRV & $15(5.6 \%)$ & $1(3.2 \%)$ & $4(3.4 \%)$ & $10(8.5 \%)$ \\
\hline HFOV & $4(1.5 \%)$ & $0(0 \%)$ & $3(2.5 \%)$ & $1(0.9 \%)$ \\
\hline
\end{tabular}


Table 1. Continued

\begin{tabular}{|c|c|c|c|c|}
\hline & Overall & Mild ARDS & Moderate ARDS & Severe ARDS \\
\hline Prone & $10(3.8 \%)$ & $0(0 \%)$ & $5(4.2 \%)$ & $5(4.3 \%)$ \\
\hline Recruitment maneuver & $128(48.1 \%)$ & $10(32.3 \%)$ & $58(49.1 \%)$ & $60(51.3 \%)$ \\
\hline $\begin{array}{l}\text { PIP in PCV, day } 1 \\
\text { mean } \pm \mathrm{SD}\left(\mathrm{cm} \mathrm{H}_{2} \mathrm{O}\right)\end{array}$ & $31 \pm 6$ & $27 \pm 5$ & $31 \pm 6$ & $32 \pm 6$ \\
\hline $\begin{array}{l}\mathrm{TV} / \mathrm{kg} \text { IBW day } 1 \\
\text { mean } \pm \mathrm{SD}(\mathrm{mL} / \mathrm{kg} \mathrm{IBW})\end{array}$ & $8.56 \pm 2.48$ & $8.71 \pm 2.22$ & $8.45 \pm 2.56$ & $8.64 \pm 2.47$ \\
\hline $\begin{array}{l}\text { PEEP, day } 1 \\
\text { mean } \pm \mathrm{SD}\left(\mathrm{cm} \mathrm{H}_{2} \mathrm{O}\right)\end{array}$ & $10 \pm 4$ & $7 \pm 3$ & $10 \pm 4$ & $12 \pm 5$ \\
\hline Neuromuscular blockade use (\%) & $94(35.3 \%)$ & $7(22.6 \%)$ & $46(39 \%)$ & $41(35 \%)$ \\
\hline Sedative drugs (\%) & 229 (86.1\%) & $25(80.6 \%)$ & $102(86.4 \%)$ & $102(87.2 \%)$ \\
\hline Morphine & $30(11.3 \%)$ & $1(3.2 \%)$ & $11(9.3 \%)$ & $18(15.4 \%)$ \\
\hline Fentanyl & $194(72.9 \%)$ & $22(71.0 \%)$ & $86(72.9 \%)$ & $86(73.5 \%)$ \\
\hline Midazolam & $197(74.0 \%)$ & $20(64.5 \%)$ & $87(73.7 \%)$ & $90(76.9 \%)$ \\
\hline Propofol & 45 (16.9\%) & $7(22.3 \%)$ & $19(16.1 \%)$ & $19(16.2 \%)$ \\
\hline $\begin{array}{l}\text { I/O balance, day } 1 \\
\text { mean } \pm \mathrm{SD}(\mathrm{mL} / \text { day })\end{array}$ & $2,484.94 \pm 2,406.92$ & $2,221.45 \pm 2,202.28$ & $2,161.26 \pm 2,145.60$ & $2,881.19 \pm 2,694.55$ \\
\hline $\begin{array}{l}\text { Total I/O balance in } 3 \text { days, } \\
\text { mean } \pm \mathrm{SD}(\mathrm{mL} / \text { day })\end{array}$ & $5,029.31 \pm 4,550$ & $3,760 \pm 3,370$ & $4,370 \pm 4,306$ & $6,037 \pm 4,892$ \\
\hline $\begin{array}{l}\text { Total I/O balance in } 7 \text { days, } \\
\text { mean } \pm \mathrm{SD}(\mathrm{mL} / \text { day })\end{array}$ & $6,634.97 \pm 6,718.06$ & $4,615.92 \pm 6,327.18$ & $5,771.69 \pm 6,947.38$ & $8,052.71 \pm 6,337.84$ \\
\hline $\begin{array}{l}\text { Enteral calories (kcal/day), AVG in } \\
7 \text { days, mean } \pm \text { SD }\end{array}$ & $673.75 \pm 546.29$ & $651.57 \pm 590.71$ & $724.63 \pm 533.06$ & $628.30 \pm 547.78$ \\
\hline Ventilator day (days), mean \pm SD & $16.46 \pm 20.11$ & $24.77 \pm 30.88$ & $16.61 \pm 17.38$ & $14.11 \pm 20.11$ \\
\hline Hospital LOS (days), mean \pm SD & $27.1 \pm 26.47$ & $34.26 \pm 33.60$ & $29.63 \pm 25.01$ & $22.65 \pm 25.26$ \\
\hline 7-day mortality, n (\%) & $83(31.1)$ & $4(12.9)$ & $30(25.4)$ & 49 (41.9) \\
\hline 28-day mortality, n (\%) & $184(69.2)$ & $16(51.6)$ & $82(69.5)$ & $86(73.5)$ \\
\hline
\end{tabular}

APACHE II, Acute Physiology and Chronic Health Evaluation; APRV, airway pressure release ventilation; ARDS, acute respiratory distress syndrome; AVG, average; BMI, body mass index; HFOV, high-frequency oscillation ventilation; HLH, hemophagocytic lymphohistiocytosis; IBW, ideal body weight; I/O, intake/output; LOS, length of stay; NIV, noninvasive ventilation; $\mathrm{PaO}_{2} / \mathrm{FiO}_{2}$, the ratio of partial pressure arterial oxygen and fraction of inspired oxygen; PCV, pressure-controlled ventilation; PEEP, positive end-expiratory pressure; PIP, peak inspiratory pressure; PSV, pressure support ventilation; SIMV, simultaneous invasive mechanical ventilation; VCV, volume-controlled ventilation; TV, tidal volume

Neuromuscular blockades and sedative drugs were prescribed to $35.3 \%$ and $86.09 \%$ of the patients, respectively. Adjunctive interventions including prone position, recruitment maneuver, and rescued modes such as airway pressure release ventilation (APRV) and HFOV were applied to patients with moderate and severe ARDS (Table 1). Noticeably, recruitment maneuver was performed in a half of the patients, especially in the patients with moderate to severe ARDS. However, the incidence of pneumothorax was not different between the patients who received recruitment maneuver (79.7\%) and who did not receive recruitment maneuver $(82 \%)$.

Overall, the crude 7-day mortality was $31.1 \%$, associated with age, ARDS severity, APACHE II score, $\mathrm{PaO}_{2} / \mathrm{FiO}_{2}$ ratio on day 1 , mean $\mathrm{PaO}_{2} / \mathrm{FiO}_{2}$ ratio during the first 3 days, fluid balance on day 1 and cumulative fluid balance during the first 3 and 7 days, and average daily calories during the first week (Table 2). The crude 28-day mortality was $68.9 \%$, associated with age, ARDS severity, APACHE II score, $\mathrm{PaO}_{2} / \mathrm{FiO}_{2}$ ratio on day 1 , mean $\mathrm{PaO}_{2} / \mathrm{FiO}_{2}$ ratio during the first 3 days, TV/kg IBW on day 1, PIP on day 1, neuromuscular blockade use, fluid balance on day 1 and cumulative fluid balance during the first 3 and 7 days, and average daily calories during the first week (Table 2). After adjusting for confounding factors, the mean $\mathrm{PaO}_{2} / \mathrm{FiO}_{2}$ ratio during the first 3 days, cumulative fluid balance on day 3 , and average daily calories during the first week were independent predictors for 7-day mortality, whereas APACHE II score, fluid balance on day 1, cumulative fluid balance during the first 
Table 2. Univariate analysis for 7- and 28-day mortalities

\begin{tabular}{|c|c|c|c|c|c|c|}
\hline \multirow[t]{2}{*}{ Univariate analysis } & \multicolumn{3}{|c|}{ 7-day mortality } & \multicolumn{3}{|c|}{ 28-day mortality } \\
\hline & Crude HR & $95 \% \mathrm{Cl}$ & $P$ & Crude HR & $95 \% \mathrm{Cl}$ & $P$ \\
\hline Age (years) & 1.015 & $1.001-1.030$ & 0.04 & 1.023 & $1.009-1.038$ & $<0.01 *$ \\
\hline \multicolumn{7}{|l|}{ Gender } \\
\hline Male (\%) & 1 & & & 1 & & \\
\hline Female (\%) & 0.742 & $0.436-1.262$ & 0.27 & 0.789 & $0.468-1.333$ & 0.38 \\
\hline BMI & 0.994 & $0.930-1.063$ & 0.87 & 0.967 & $0.906-1.031$ & 0.31 \\
\hline \multicolumn{7}{|l|}{ ARDS severity } \\
\hline Mild & 1 & & & 1 & & \\
\hline Moderate & 2.301 & $0.744-7.115$ & 0.15 & 2.135 & $0.954-4.781$ & 0.07 \\
\hline Severe & 4.684 & $1.599-14.795$ & $<0.01^{*}$ & 2.601 & $1.151-5.878$ & $0.02^{*}$ \\
\hline APACHE II & 1.108 & $1.060-1.159$ & $<0.01^{*}$ & 1.101 & $1.055-1.150$ & $<0.01^{*}$ \\
\hline $\mathrm{PaO}_{2} / \mathrm{FiO}_{2}$ ratio, day 1 & 0.992 & $0.987-0.997$ & $<0.01^{*}$ & 0.997 & 0.993-1.001 & 0.18 \\
\hline Mean $\mathrm{PaO}_{2} / \mathrm{FiO}_{2}$ ratio & 0.99 & $0.980-0.992$ & $<0.01^{*}$ & 0.994 & $0.990-0.998$ & $<0.01^{*}$ \\
\hline TV/kg IBW, day 1 & 0.996 & $0.883-1.124$ & 0.95 & 0.914 & $0.810-1.031$ & 0.14 \\
\hline Mean TV/kg IBW & 0.924 & $0.801-1.067$ & 0.28 & 0.917 & $0.802-1.048$ & 0.20 \\
\hline PEEP, day 1 & 1.006 & $0.948-1.067$ & 0.85 & 0.966 & $0.911-1.024$ & 0.25 \\
\hline Mean PEEP & 1.030 & $0.965-1.100$ & 0.37 & 0.994 & $0.931-1.062$ & 0.86 \\
\hline PIP, day 1 & 1.061 & $1.004-1.121$ & 0.04 & 1.040 & $0.983-1.101$ & 0.17 \\
\hline Recruitment maneuver & 0.910 & $0.542-1.529$ & 0.77 & 1.312 & $0.778-2.211$ & 0.31 \\
\hline Pneumothorax & 0.478 & $0.226-1.008$ & 0.05 & 1.079 & $0.553-2.104$ & 0.82 \\
\hline Neuromuscular blockade & 0.718 & $0.412-1.252$ & 0.22 & 1.471 & $0.840-2.578$ & 0.18 \\
\hline I/O balance, day 1 (L/day) & 1.325 & $1.175-1.495$ & $<0.01^{*}$ & 1.200 & $1.063-1.354$ & $<0.01^{*}$ \\
\hline Total I/O balance in 3 days (L/day) & 1.229 & $1.142-1.324$ & $<0.01^{*}$ & 1.137 & $1.066-1.212$ & $<0.01^{*}$ \\
\hline Total I/O balance in 7 days (L/day) & 1.112 & $1.071-1.176$ & $<0.01^{*}$ & 1.128 & $1.077-1.181$ & $<0.01^{*}$ \\
\hline 7-day AVG enteral calories (kcal/day) & 0.998 & $0.997-0.999$ & $<0.01^{*}$ & 0.999 & $0.998-0.999$ & $<0.01^{*}$ \\
\hline
\end{tabular}

APACHE II, Acute Physiology and Chronic Health Evaluation; ARDS, acute respiratory distress syndrome; AVG, average; BMI, body mass index; $\mathrm{Cl}$, confidence interval; $\mathrm{HR}$, hazard ratio; IBW, ideal body weight; I/O, intake/output; mean $\mathrm{PaO}_{2} / \mathrm{FiO}_{2}$ ratio, mean $\mathrm{PaO}_{2} / \mathrm{FiO}$ ratio in the first 3 days; mean PEEP, mean PEEP in the first 3 days; mean TV/kg IBW, mean TV/kg IBW in the first 3 days; $\mathrm{PaO}_{2} / \mathrm{FiO}_{2}$ ratio, the ratio of partial pressure arterial oxygen and fraction of inspired oxygen; PEEP, positive end-expiratory pressure; PIP, peak inspiratory pressure; TV, tidal volume

*Statistical significance

7 days, and average daily calories during the first week were independent predictors for 28-day mortality (Table 3). Furthermore, the patients who received average daily calories during the first week of $<60 \%$ of estimated daily energy requirement had a greater risk of death $(\mathrm{OR}=3.28$, 95\% CI 1.79-6.01, $P<0.001)$. Moreover, interestingly, the risk of death within 28 days increased with increasing 7-day cumulative fluid balance as shown in Figure 1.

\section{Discussion}

This study demonstrated that the 28-day mortality of the ARDS patients admitted in our medical ICUs was high, compared with the mortalities in other studies [15-19] (Table 4). We postulated that the higher mortality rate resulted from limited ICU beds, delayed ICU admission, delayed sedative and neuromuscular blockade administration, and shortage of medical staff. Our mortality rate tended to be increasing with the greater ARDS severity; however, it was not significant. It might be explained that there were multiple factors affecting the mortality rate such as ventilatorinduced lung injury, ventilator-associated pneumonia, and positive cumulative fluid balance. Noticeably, $42.3 \%$ of our patients received TV greater than $8 \mathrm{~mL} / \mathrm{kg}$ IBW on the first day, compared with $30 \%$ of the patients in the PRoVENT study [19]. Moreover, there were limited data of the Pplat in our study (4\%), compared with $17.2 \%$ in ALIEN [18], 40\% in 
Table 3. Multivariate analysis for 7- and 28-day mortalities

\begin{tabular}{|c|c|c|c|c|c|c|}
\hline \multirow[t]{2}{*}{ Multivariate analysis } & \multicolumn{3}{|c|}{ 7-day mortality ${ }^{+}$} & \multicolumn{3}{|c|}{ 28-day mortality ${ }^{\ddagger}$} \\
\hline & Adjusted HR & $95 \% \mathrm{Cl}$ & $P$ & Adjusted HR & $95 \% \mathrm{Cl}$ & $P$ \\
\hline Age (years) & 1.004 & $0.985-1.023$ & 0.70 & 1.002 & $0.979-1.027$ & 0.63 \\
\hline \multicolumn{7}{|l|}{ ARDS severity } \\
\hline Mild & 1 & & & 1 & & \\
\hline Moderate & 1.608 & $0.308-8.388$ & 0.57 & 7.65 & $0.878-66.662$ & 0.66 \\
\hline Severe & 1.835 & $0.204-16.539$ & 0.59 & 14.00 & $0.715-274.194$ & 0.82 \\
\hline APACHE II & 1.050 & $0.995-1.108$ & 0.94 & 1.151 & $1.073-1.235$ & $<0.01^{*}$ \\
\hline $\mathrm{PaO}_{2} / \mathrm{FiO}_{2}$ ratio, day 1 & 1.003 & $0.995-1.011$ & 0.50 & 1.003 & $0.994-1.013$ & 0.46 \\
\hline Mean $\mathrm{PaO}_{2} / \mathrm{FiO}_{2}$ ratio & 0.988 & $0.981-0.994$ & $<0.01^{*}$ & 0.997 & $0.989-1.006$ & 0.55 \\
\hline TV/kg IBW, day 1 & & & & 1.001 & $0.997-1.004$ & 0.68 \\
\hline PIP, day 1 & & & & 1.037 & $0.966-1.114$ & 0.32 \\
\hline Neuromuscular blockade & & & & 1.218 & $0.524-2.832$ & 0.65 \\
\hline $\begin{array}{l}\text { I/O balance, day } 1 \\
\text { (L/day) }\end{array}$ & 0.984 & $0.818-1.182$ & 0.86 & 0.816 & $0.666-0.998$ & $0.048^{*}$ \\
\hline Total I/O balance in 3 days (L/day) & 1.192 & $1.102-1.289$ & $<0.01^{*}$ & 0.969 & $0.802-1.169$ & 0.74 \\
\hline Total I/O balance in 7 days (L/day) & 1.061 & $0.979-1.150$ & 0.15 & 1.103 & $1.026-1.186$ & $<0.01^{*}$ \\
\hline 7-day AVG enteral calories (kcal/day) & 0.998 & $0.997-0.999$ & $<0.01^{*}$ & 0.999 & $0.998-1$ & $<0.01^{*}$ \\
\hline
\end{tabular}

APACHE II, Acute Physiology and Chronic Health Evaluation; ARDS, acute respiratory distress syndrome; AVG, average; BMI, body mass index; $\mathrm{Cl}$, confidence interval; $\mathrm{HR}$, hazard ratio; IBW, ideal body weight; I/O, intake/output; mean $\mathrm{PaO}_{2} / \mathrm{FiO}_{2}$ ratio, mean $\mathrm{PaO}_{2} / \mathrm{FiO}_{2}$ ratio in the first 3 days; $\mathrm{PaO}_{2} / \mathrm{FiO}_{2}$ ratio, the ratio of partial pressure arterial oxygen and fraction of inspired oxygen; PEEP, positive end-expiratory pressure; PIP, peak inspiratory pressure; TV, tidal volume

${ }^{\dagger}$ Adjusted age, ARDS severity, APACHE II score, mean $\mathrm{PaO}_{2} / \mathrm{FiO}_{2}$ ratio during the first 3 days, fluid balance on day 1 and cumulative fluid balance during the first 3 and 7 days, and AVG daily calories during the first week for 7-day morality

${ }^{\ddagger}$ Adjusted age, ARDS severity, APACHE II score, $\mathrm{PaO}_{2} / \mathrm{FiO}_{2}$ ratio on day 1, mean $\mathrm{PaO}_{2} / \mathrm{FiO}_{2}$ ratio during the first 3 days, TV/kg IBW on day 1, $\mathrm{PIP}$ on day 1 , neuromuscular blockade use, fluid balance on day 1 and cumulative fluid balance during the first 3 and 7 days, and AVG daily calories during the first week for 28-day mortality

*Statistical significance

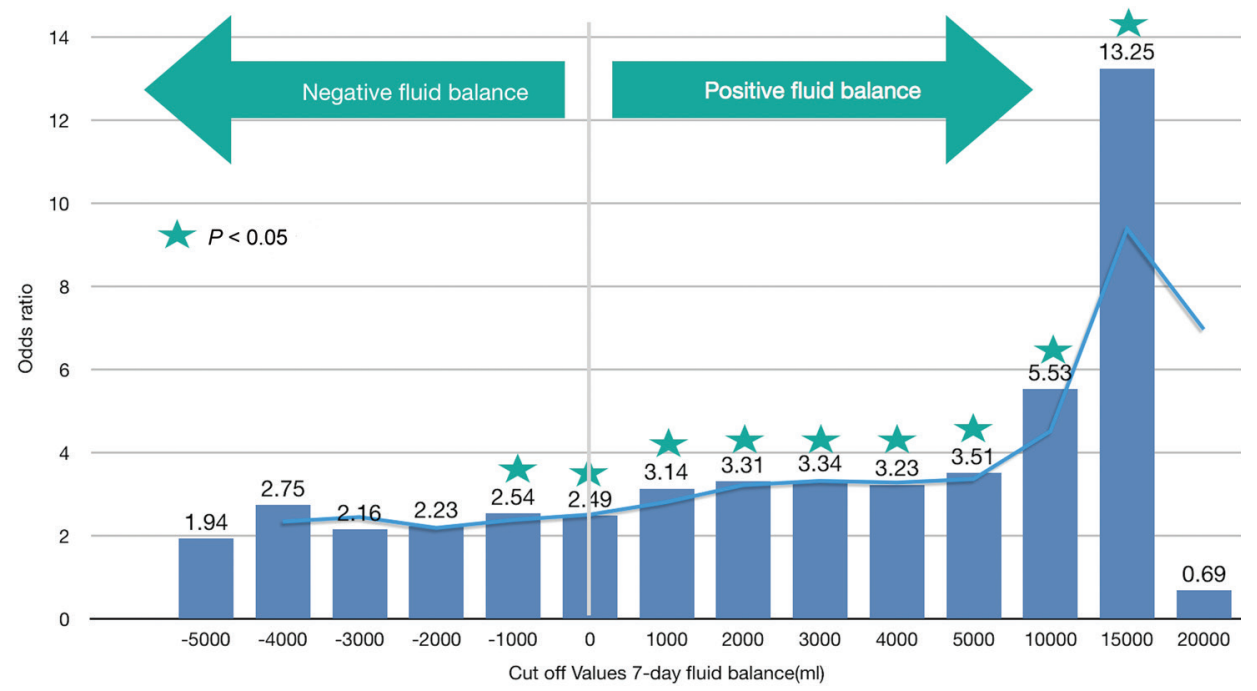

Figure 1. The increasing OR of 28-day mortality in patients who had more positive 7-day cumulative fluid balance. OR, odds ratio 
Table 4. Comparison of 28-day mortality of ARDS patients and factors possibly associated with mortality between our study and other studies including ALIEN, LUNG SAFE, PRoVENT, and APRONET

\begin{tabular}{|c|c|c|c|c|c|}
\hline Study period & $\begin{array}{l}\text { Our study } \\
\text { 2010-2014 }\end{array}$ & $\begin{array}{c}\text { ALIEN } \\
\text { [18] } \\
\text { 2008-2009 }\end{array}$ & $\begin{array}{c}\text { LUNG SAFE } \\
\text { [15] } \\
2014\end{array}$ & $\begin{array}{c}\text { PRoVENT } \\
\text { [19] } \\
\text { 2014-2015 }\end{array}$ & $\begin{array}{c}\text { APRONET } \\
{[20]} \\
2016-2017\end{array}$ \\
\hline \multicolumn{6}{|l|}{ 28-day mortality } \\
\hline All severity of ARDS & $69.2 \%$ & $42.7 \%$ & $34.8 \%$ & $29 \%$ & NA \\
\hline Mild ARDS & $51.6 \%$ & NA & $29.6 \%$ & NA & NA \\
\hline Moderate ARDS & $69.5 \%$ & NA & $35.2 \%$ & NA & NA \\
\hline Severe ARDS & $73.5 \%$ & NA & $40.9 \%$ & NA & NA \\
\hline \multicolumn{6}{|l|}{ Factors } \\
\hline $\mathrm{TV}(\mathrm{mL} / \mathrm{kg} \mathrm{IBW})$ on day 1 & $8.56 \pm 2.48$ & $7.2 \pm 1.1$ & 7.6 & 7.6 & 6.7 \\
\hline Percentage of patients with TV $>8 \mathrm{~mL} / \mathrm{kg}$ IBW on day 1 & $42.3 \%$ & NA & NA & $30 \%$ & NA \\
\hline Percentage of Pplat measurement & $4 \%$ & $17.2 \%$ & $40 \%$ & $41 \%$ & $90.7 \%$ \\
\hline Percentage of patients with prone position (in severe ARDS) & $4 \%$ & NA & $16 \%$ & NA & $32.9 \%$ \\
\hline Percentage of patients receiving neuromuscular blockage & $35.3 \%$ & NA & $21.7 \%$ & NA & NA \\
\hline Percentage of patients with recruitment maneuver & $48.1 \%$ & NA & $20.9 \%$ & NA & NA \\
\hline Percentage of patients with ECMO & $0 \%$ & NA & $3.2 \%$ & NA & $1.9 \%$ \\
\hline Percentage of patients with HFOV & $1.5 \%$ & NA & $1.2 \%$ & NA & NA \\
\hline Percentage of patients with APRV & $5.63 \%$ & NA & NA & NA & NA \\
\hline
\end{tabular}

APRV, airway pressure release ventilation; ARDS, acute respiratory distress syndrome; ECMO, extracorporeal membrane oxygenation; HFOV, high-frequency oscillatory ventilation; IBW, ideal body weight; Pplat, plateau pressure; TV, tidal volume; NA, not available

LUNG SAFE [15], 41\% in PRoVENT [19], and $90.7 \%$ in APRONET [20]. These findings might indicate that the physicians less concerned about ventilator-induced lung injury. Furthermore, the prevalence of prone position in our severe ARDS patients was only $4 \%$, compared with $16 \%$ in LUNG SAFE [15] and 32.9\% in APRONET [20]. Prone position was infrequently used in our study because of different study periods. The PROSEVA [6] reported the mortality benefit of prone position in 2013, but we retrospectively reviewed the data between 2010 and 2014. In addition, the prevalence of the use of neuromuscular blocking agent was $35.3 \%$ in our study, higher than LUNG SAFE (21.7\%) [15] due to the higher proportion of severe ARDS patients in our study. Despite the greater use of neuromuscular blockade, the mortality rate was higher, which might be from inadequate doses of this medication and no ventilator asynchrony monitoring. Recruitment maneuver was performed to $48.12 \%$ of the patients, which was quite high, compared with $20.9 \%$ in the LUNG SAFE [15]. Despite the fact that the recruitment maneuver potentially increased the risk of barotrauma and death [21, 22], our study did not show the association between the procedure and the complications. Finally, similar to other studies, there were low prevalence of HFOV, APRV, and extracorporeal membrane oxygenation (ECMO) use, which less affected the ARDS outcomes [7, 8, 23-29].

According to the ventilator complications, barotrauma was not different between ARDS survivors and non-survivors. Nevertheless, ventilator-associated pneumonia was higher in the non-survivors group (18.4\% vs $13.4 \%$ ).

Besides, most of the patients had positive cumulative fluid balance, which contributed to the significantly greater mortality in our study (Figure 1). Compared with FACTT [10], our ARDS patients had cumulative fluid balance over 7 days close to the fluid balance of the patients in the liberal fluid management group $(6,634.97 \pm 6,718.06 \mathrm{~mL}$ in our study vs 6,992 \pm 502 in liberal FACTT), who had worse clinical outcomes, including less ventilator-free days and deteriorated oxygenation index and lung injury score. Nevertheless, FACTT did not demonstrate the mortality risk from liberal fluid management. The different findings might be explained by the fact that there were limited data of hemodynamic status, which possibly confounded to the significantly higher mortality rate in our study.

Furthermore, our study showed that the patients receiving daily calories less than $60 \%$ of the estimated daily caloric need during the first week had higher mortality. This result was different from the findings in the EDEN study [30], which demonstrated that initial trophic enteral feeding for up to 
6 days in patients with acute lung injury resulted in similar ventilator-free days, 60-day mortality, and infectious complications, compared with full enteral feeding. It might be explained that our patients with lower caloric intake possibly had more severe conditions such as hemodynamic instability or severe lung injury treated with prone position, which had an impact on mortality outcome.

Our study had limitations. Due to the retrospective design, the information was obtained from the recorded documents. Thus, there were some missing data such as height, body weight, Pplat, and driving pressure. In addition, there might be uncontrolled factors confounding to the mortality rate such as inadequate antibiotics and source control, inappropriate resuscitation of shock, or the different severity of comorbidities.

\section{Conclusion}

The 28-day mortality of ARDS was high. In addition, the average TV and fluid balance were greater than the protective limits. These findings indicated the potential improvement of ARDS outcomes in our hospital. The educational program focusing on ARDS management, follow-up, and feedback activities should be provided to our medical personnel.

Author contributions. Both NS and NK contributed substantially to the conception and design of this study. NS contributed to the acquisition of data. NS and NK analyzed and interpreted the data. NS drafted the manuscript. NK contributed to its critical revision. Both NS and NK approved the final version submitted for publication and take responsibility for the statements made in the published article.

Acknowledgments. A part of this study was presented at the 21 st Congress of the Asian Pacific Society of Respirology and published in the poster presentation abstract in Respirology. 2016; 21(Suppl. 3):3-213.

Conflict of interest statement. The authors have completed and submitted the International Committee of Medical Journal Editors Uniform Disclosure Form for Potential Conflicts of Interest. None of the authors disclose any conflict of interest.

\section{References}

[1] Ashbaugh DG, Bigelow DB, Petty TL, Levine BE. Acute respiratory distress in adults. Lancet. 1967; 2:319-23.

[2] Bernard GR, Artigas A, Brigham KL, Carlet J, Falke K, Hudson L, et al. The American-European Consensus Conference on ARDS.
Definitions, mechanisms, relevant outcomes, and clinical trial coordination. Am J Respir Crit Care Med. 1994; 149:818-24.

[3] ARDS Definition Task Force, Ranieri VM, Rubenfeld GD, Thompson BT, Ferguson ND, Caldwall E, et al. Acute respiratory distress syndrome: the Berlin definition. JAMA. 2012; 307:2526-33.

[4] Acute Respiratory Distress Syndrome Network, Brower RG, Matthay MA, Morris A, Schoenfeld D, Thompson BT, et al. Ventilation with lower tidal volumes as compared with traditional tidal volumes for acute lung injury and the acute respiratory distress syndrome. The Acute Respiratory Distress Syndrome Network. N Engl J Med. 2000; 342:1301-8

[5] Papazian L, Forel JM, Gacouin A, Penot-Ragon C, Perrin G, Loundou A, et al. Neuromuscular blockers in early acute respiratory distress syndrome. N Engl J Med. 2010; 363:1107-16.

[6] Guerin C, Reignier J, Richard JC, Beuret P, Gacouin A, Boulain T, et al. Prone positioning in severe acute respiratory distress syndrome. N Engl J Med. 2013; 368:2159-68.

[7] Ferguson ND, Cook DJ, Guyatt GH, Mehta S, Hand L, Austin P, et al. High-frequency oscillation in early acute respiratory distress syndrome. N Engl J Med. 2013; 368:795-805.

[8] Young D, Lamb SE, Shah S, MacKenzie I, Tunnicliffe W, Lall R, et al. High-frequency oscillation for acute respiratory distress syndrome. N Engl J Med. 2013; 368:806-13.

[9] Writing Group for the Alveolar Recruitment for Acute Respiratory Distress Syndrome Trial (ART) Investigators, Cavalcanti AB, Suzumura ÉA, Laranjeira LN, Paisani DM, Damiani LP, et al. Effect of lung recruitment and titrated positive end-expiratory pressure (PEEP) vs low PEEP on mortality in patients with acute respiratory distress syndrome: a randomized clinical trial. JAMA. 2017; 318:1335-45.

[10] Wiedemann HP, Wheeler AP, Bernard GR, Thompson BT, Hayden D, deBoisblanc B, et al. Comparison of two fluidmanagement strategies in acute lung injury. N Engl J Med. 2006; 354:2564-75.

[11] Sakr Y, Vincent JL, Reinhart K, Groeneveld J, Michalopoulos A, Sprung CL, et al. High tidal volume and positive fluid balance are associated with worse outcome in acute lung injury. Chest. 2005; 128:3098-108.

[12] Schuller D, Mitchell JP, Calandrino FS, Schuster DP. Fluid balance during pulmonary edema. Is fluid gain a marker or a cause of poor outcome? Chest. 1991; 100:1068-75.

[13] Humphrey H, Hall J, Sznajder I, Silverstein M, Wood L. Improved survival in ARDS patients associated with a reduction in pulmonary capillary wedge pressure. Chest. 1990; 97:1176-80.

[14] Mikkelsen ME, Christie JD, Lanken PN, Biester RC, Thompson BT, Bellamy SL, et al. The adult respiratory distress syndrome cognitive outcomes study: long-term neuropsychological function in survivors of acute lung injury. Am J Respir Crit Care Med. 2012; 185:1307-15.

[15] Giacomo B, John G, Tai P, Eddy F, Laurent B, Andres E, et al. Epidemiology, patterns of care, and mortality for patients with acute respiratory distress syndrome in intensive care units in 50 countries. JAMA. 2016; 315:788-800.

[16] Phua J, Badia JR, Adhikari NK, Friedrich JO, Fowler RA, Singh JM, et al. Has mortality from acute respiratory distress syndrome decreased over time?: a systematic review. Am J Respir Crit Care Med. 2009; 179:220-7.

[17] Zambon M, Vincent JL. Mortality rates for patients with acute lung injury/ARDS have decreased over time. Chest. 2008; 133:1120-7. 
[18] Jesus V, Jesus B, Jose MA, Antonio S, Luis B, Alfonso A, et al. The ALIEN study: incidence and outcome of acute respiratory distress syndrome in the era of lung protective ventilation. Intensive Care Med. 2011; 37:1932-41.

[19] Ary SN, Carmen S, Fabienne D, Antonio A, Jaume C, Rogier M, et al. Epidemiological characteristics, practice of ventilation, and clinical outcome in patients at risk of acute respiratory distress syndrome in intensive care units from 16 countries (PRoVENT): an international, multicentre, prospective study. Lancet. 2016; 4:882-93.

[20] Guerin C, Beuret P, Constantin JM, Belani G, Garcia-Olivares P, Roca $\mathrm{O}$, et al. A prospective international observational prevalence study on prone positioning of ARDS patients: the APRONET (ARDS Prone Position Network) study. Intensive Care Med. 2018; 44:22-37.

[21] Huh JW, Jung H, Choi HS, Hong SB, Lim CM, Koh Y. Efficacy of positive end-expiratory pressure titration after the alveolar recruitment manoeuvre in patients with acute respiratory distress syndrome. Crit Care. 2009; 13:R22.

[22] Meade MO, Cook DJ, Guyatt GH, Slutsky AS, Arabi YM, Cooper DJ, et al. Ventilation strategy using low tidal volumes, recruitment maneuvers, and high positive end-expiratory pressure for acute lung injury and acute respiratory distress syndrome: a randomized controlled trial. JAMA. 2008; 299:637-45.

[23] Li JQ, Li N, Han GJ, Pan CG, Zhang YH, Shi XZ, et al. Clinical research about airway pressure release ventilation for moderate to severe acute respiratory distress syndrome. Eur Rev Med Pharmacol Sci. 2016; 20:2634-41.
[24] Lim J, Litton E, Robinson H, Das Gupta M. Characteristics and outcomes of patients treated with airway pressure release ventilation for acute respiratory distress syndrome: A retrospective observational study. J Crit Care. 2016; 34:154-9.

[25] Song S, Tian H, Yang X, Hu Z. The clinical effect of airway pressure release ventilation for acute lung injury/acute respiratory distress syndrome. Zhonghua Wei Zhong Bing Ji Jiu Yi Xue. 2016; 28:15-21.

[26] Sud S, Sud M, Friedrich JO, Adhikari NK. Effect of mechanical ventilation in the prone position on clinical outcomes in patients with acute hypoxemic respiratory failure: a systematic review and meta-analysis. CMAJ. 2008; 178:1153-61.

[27] Calfee CS, Matthay MA. Nonventilatory treatments for acute lung injury and ARDS. Chest. 2007; 131:913-20.

[28] Peek GJ, Elbourne D, Mugford M, Tiruvoipati R, Wilson A, Allen E, et al. Randomised controlled trial and parallel economic evaluation of conventional ventilatory support versus extracorporeal membrane oxygenation for severe adult respiratory failure (CESAR). Health Technol Assess. 2010; 14:1-46.

[29] Peek GJ, Mugford M, Tiruvoipati R, Wilson A, Allen E, Thalanany $\mathrm{MM}$, et al. Efficacy and economic assessment of conventional ventilatory support versus extracorporeal membrane oxygenation for severe adult respiratory failure (CESAR): a multicentre randomised controlled trial. Lancet. 2009; 374:1351-63.

[30] National Heart, Lung, and Blood Institute Acute Respiratory Distress Syndrome (ARDS) Clinical Trials Network, Rice TW, Wheeler AP, Thompson BT, Steingrub J, Hite RD, et al. Initial trophic vs full enteral feeding in patients with acute lung injury the EDEN randomized trial. JAMA. 2012; 307:795-803. 